\title{
Conservative treatment of cysts of the cavum septum pellucidum presenting in childhood: report of 3 cases
}

\author{
Gyang Markus Bot, BM BCh, Shlomi Constantini, MD, MSc, and Jonathan Roth, MD \\ Department of Pediatric Neurosurgery, Dana Children's Hospital, Tel-Aviv Medical Center, Tel-Aviv University, Tel-Aviv, Israel
}

\begin{abstract}
Cavum septum pellucidum (CSP) cysts are relatively rare. The most common presenting symptom is headache, which is thought to be secondary to elevated intracranial pressure. Many CSP cysts are treated surgically; conservative treatment is seldom recommended. The authors describe 3 cases of pediatric CSP cysts that were managed without surgery.

The patients ranged in age from 5 months to 8 years old. Two presented with headaches, which were associated with mild ventricular enlargement in 1 case. Over the course of 5-15 months, 2 cysts became markedly reduced in size, and in one of these 2 cases a substantial reduction in ventricle size was also observed. At last follow-up, all 3 children were asymptomatic.
\end{abstract}

The authors note that CSP cysts are often associated with headaches. In the absence of hydrocephalus, they recommend conservative management with clinical and radiological follow-up.

http://thejns.org/doi/abs/10.3171/2015.3.PEDS14714

KEY WORDS cavum septum pellucidum; cyst; conservative; childhood; congenital

$\mathrm{T}$ HE cavum septum pellucidum (CSP), also known as the fifth ventricle, is a slit-like fluid collection between the two leaflets of the septum pellucidum. CSP is common among newborns, gradually disappearing during infancy as the two leaflets of the septum unite. About $85 \%$ of term neonates have a CSP, and $12 \%$ of those persist and may still found in children from 6 months to 16 years of age. ${ }^{7}$ A CSP may also be found in about $17 \%$ of adults..$^{18}$ The finding is sometimes associated with repetitive head injuries, such as in boxers, and CSP is found at a higher rate among schizophrenics. ${ }^{15}$

CSP cysts are defined as a lateral bowing of the septum pellucidum with a width greater than $1 \mathrm{~cm} .{ }^{19}$ These cysts are relatively rare, with a prevalence among patients undergoing imaging studies of approximately $0.04 \% .{ }^{23}$ There is no agreement regarding the clinical importance of these lesions. Often, they are diagnosed during brain imaging performed for headaches, and thus have been associated with headaches. However, in the absence of hydrocephalus, this association, and whether there is a cause-effect relationship, is not clear.

The natural history of CSP cysts is also unclear. Because the cysts typically come to attention when the patients have symptoms, they are often treated surgically and not just managed conservatively, with imaging and clinical follow-up. ${ }^{8,17,22,24}$ Spontaneous regression of CSP cysts has been reported in only 3 cases involving adults. ${ }^{11,14,19}$
We present our experience treating 3 children with CSP cysts and discuss the natural history of these lesions. Among these cases, we describe, for the first time in the literature, spontaneous resolution of CSP cysts in pediatric patients.

\section{Case Reports}

\section{Case 1}

A 5-month-old previously healthy baby boy presented due to increasing head circumference with otherwise normal neurological findings. According to his prenatal and neonatal history, dilated ventricles had been diagnosed in utero (having been seen on both ultrasonography and MRI). Ultrasound examination of the infant's head completed after delivery revealed a CSP cyst.

An MRI study performed when he was 5 months of age revealed external hydrocephalus and confirmed the presence of a CSP cyst (Fig. 1). About 5 months later, another MRI study was performed, and this showed spontaneous resolution of the CSP cyst and the external hydrocephalus pattern. The child remains neurologically intact.

\section{Case 2}

A 4-year-old girl presented with headaches and vomiting. The results of neurological and ophthalmological examinations were normal. MRI showed a CSP cyst with no 

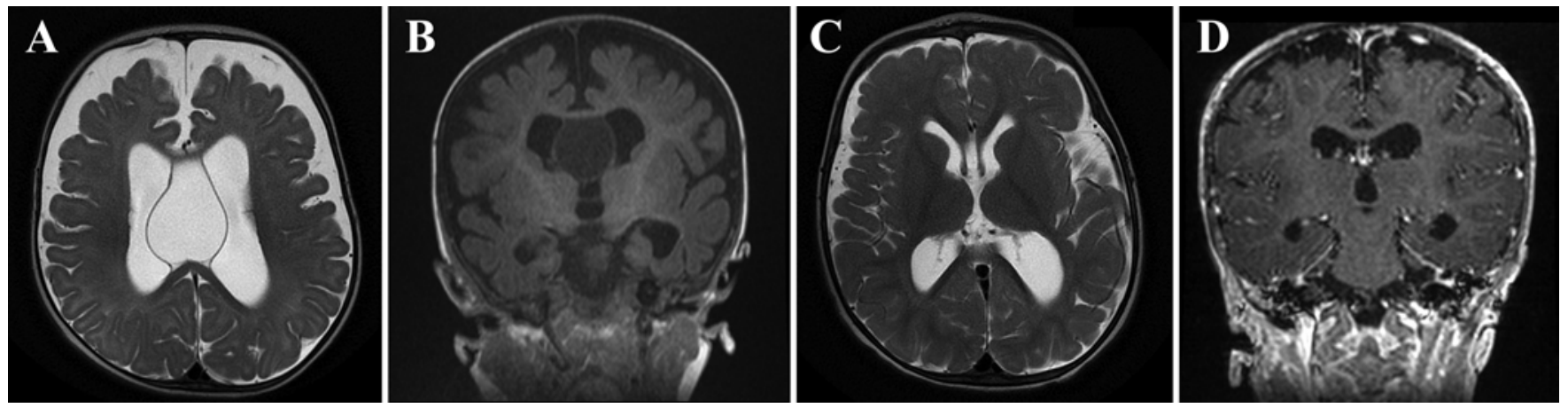

FIG. 1. Case 1. A and B: Initial axial T2-weighted (A) and coronal T1-weighted (B) MR images showing a CSP cyst. C and D: Axial T2-weighted (C) and coronal Gd-enhanced T1-weighted (D) MR images obtained 5 months later showing spontaneous resolution of the cyst.

hydrocephalus (Fig. 2). The child's symptoms were diagnosed as migraine-like. Over the course of several months the symptoms gradually resolved. A follow-up MRI study performed 13 months later showed a stable CSP (with the cyst remaining the same size).

\section{Case 3}

An 8-year-old boy with a history of premature birth (delivered at 35 weeks of gestation) presented with recent headaches and vomiting. On examination he was found to have mild papilledema. Brain MRI showed a CSP cyst with mild enlargement of the lateral ventricles (Fig. 3). His symptoms were presumed to be secondary to increased intracranial pressure. Surgical fenestration of the cyst was contemplated; however, as it seemed that the child's headaches were subsiding, his parents opted for close followup. Over a period of 3 weeks, the child's clinical condition improved, with headaches occurring only during the Valsalva maneuver and gradually subsiding. Since that time the headaches and papilledema have resolved. A follow-up MRI study performed 15 months later showed reduction in the CSP cyst and size of lateral ventricles.

\section{Discussion}

CSP cysts are relatively rare. Their clinical correlates, natural history, and treatment indications remain controversial. We describe 3 pediatric cases of CSP cysts that were managed conservatively. Two patients presented with headaches and vomiting, symptoms which were attributed to increased intracranial pressure (ICP) in 1 case. In 2 cases there was a meaningful spontaneous reduction in the size of the cyst. In the other case, the imaging findings were stable. Symptoms resolved in the 2 symptomatic patients.

The literature regarding CSP cysts is conflicting. Previous reports have described an association between CSP cysts, and even just CSP, and headaches, and described various surgical treatments for these cysts. We are all familiar with the wise French saying: En médecine, comme en amour, ni jamais, ni toujours. (In medicine, as in love, never say never, and never say always.) Nevertheless, we would like to state that a CSP cyst without hydrocephalus is never a surgical entity! The ventricle borders do not harbor pain fibers; however, the choroid plexus and paraventricular vessels may contain pain fibers. ${ }^{26}$ Even large masses sitting within the ventricular system do not produce headache before hydrocephalus develops.

\section{Differential Diagnosis}

Several midline lesions may mimic CSP cysts. These include various neoplastic lesions (such as tumors of the lateral ventricle or the septum pellucidum), epidermoid cysts (which may resemble CSF signals on MRI), and various CSF cysts. ${ }^{22}$

Suprasellar arachnoid cysts may protrude upward,
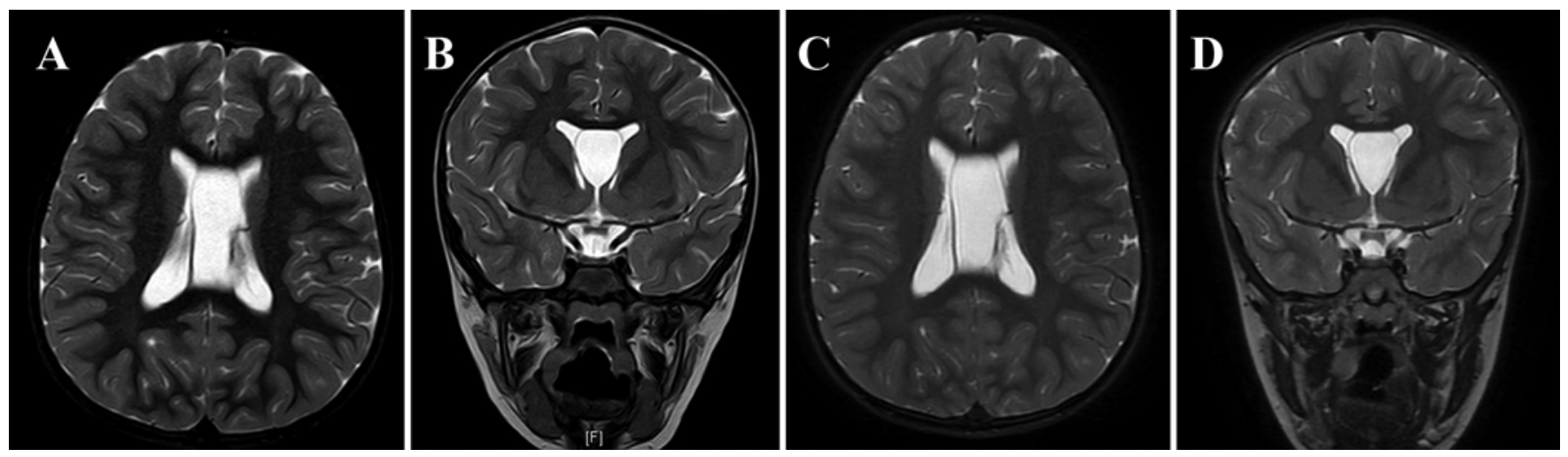

FIG. 2. Case 2. A and B: Initial axial (A) and coronal (B) T2-weighted MR images showing a CSP cyst. C and D: Axial (C) and coronal (D) T2-weighted MR images obtained 13 months later showing stability. 

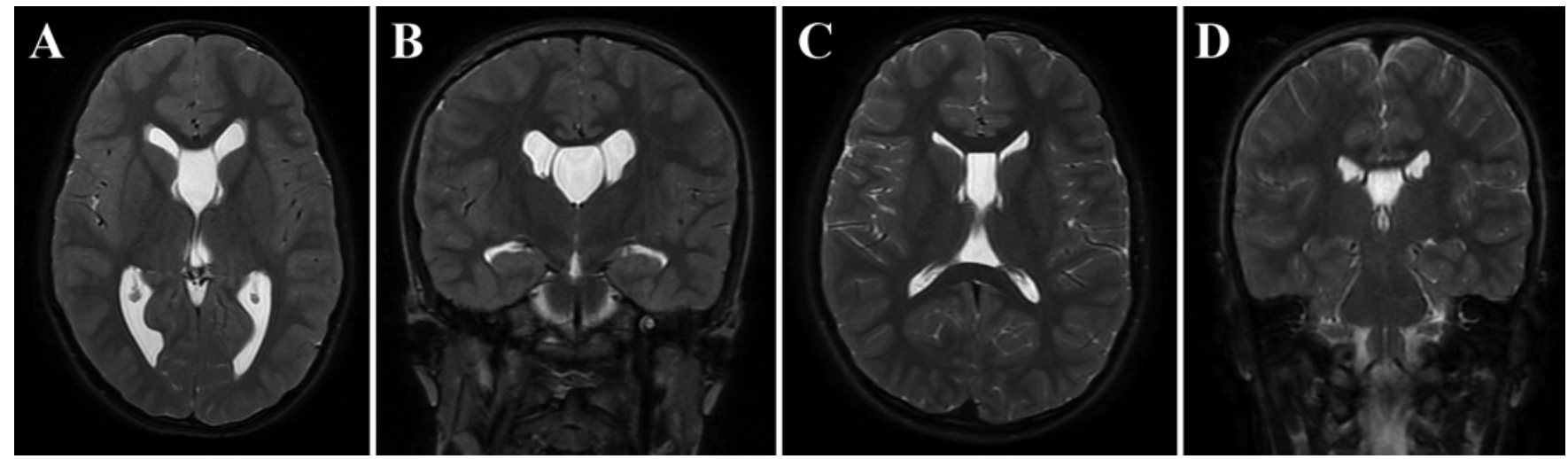

FIG. 3. Case 3. A and B: Initial axial (A) and coronal (B) T2-weighted MR images showing a CSP cyst. C and D: Axial (C) and coronal (D) T2-weighted MR images obtained 15 months later showing partial resolution of the cyst.

elevating the floor of the third ventricle and causing obstructive hydrocephalus. Quadrigeminal cistern arachnoid cysts may compress the tectal-aqueductal region, leading to obstructive hydrocephalus too. Cavum vergae (located caudal to the fornices) may resemble a CSP cyst but does not extend anteriorly to the full extent of the septum pellucidum. The most common differential diagnosis of CSP cyst is CSP with no cyst. This is a common finding, and differentiated from CSP cyst by size $(<1 \mathrm{~cm}$ width) and lack of lateral bowing of the septal leaflets. ${ }^{19}$

\section{Clinical Presentation}

Symptoms related to CSP cysts are thought to result from 1 or more of the following 4 mechanisms: ${ }^{7,15}$

1. Increased intracranial pressure. This occurs as a result of obstruction of the interventricular foramen of Monro by the cyst via a ball-valve phenomenon. Aboulker et al. first described the cyst obstructing the interventricular foramen radiographically and Amin proposed the development of obstructive hydrocephalus based on intermittent obstruction. $1,4,7,15$

2. Compression of the hypothalamoseptal triangle, which is located within the region bounded by a line from the posterior aspect of the anterior commissure to the dorsal surface of the optic chiasma to the junction of the rostrum and genu of the corpus callosum and back to the anterior commissure. Compression of this region is responsible for neuropsychiatric, autonomic, and visual symptoms. Some of these symptoms include emotional lability, bizarre behavior, change in mental status, decline in academic performance, sleep disturbance, enuresis, incontinence, anorexia, abnormal epigastric sensation, disturbance in sleep pattern, hypothermia, and weight loss. ${ }^{7,15}$

3. Distortion of vascular structures with deep venous drainage impairment. Dandy first described the distortion in vascular structures while Aoki noticed the chronic impairment in deep venous drainage. ${ }^{5,9,15}$

4. Compression of visual structures. The visual structures can be compressed either directly, by the cyst, or indirectly, as a result of hydrocephalus. ${ }^{13,15}$ The patient can present with nystagmus, sixth cranial nerve palsy, impaired visual acuity, visual field defects, papilledema, optic pallor, and retinal hemorrhages. ${ }^{15}$
The most common treatment indication, however, is headache-often with no associated significant hydrocephalus. ${ }^{7}$ Headache is a very common phenomenon in the general population; about $50 \%$ of adults report suffering from headaches over the previous year. ${ }^{6,21}$ It is estimated that about $60 \%$ of children will complain of headaches during childhood. ${ }^{2}$ The causes of headaches are frequently multifactorial, and psychological factors are often underappreciated. The theory that the headache in the context of a CSP cyst is due to transient hydrocephalus is unproven. Many patients with headache and CSP, with or without a cyst, are undergoing imaging examinations; transient ventricular enlargement is rare. Despite this, the patient in our Case 3 showed lateral ventricular mild dilation and was offered surgery. However, his symptoms eventually subsided and so did the ventricular dilation. In patients with headaches that are possibly associated with the CSP cysts, even in the absence of hydrocephalus, an intracranial pressure measurement may clarify whether there is a need for surgery.

Similar discussions on the relationship of headache and pineal cysts were common during the 1980s and 1990s, and are still ongoing today. At that time, it was also quite common to operate on these patients. Magnificent approaches to the pineal region were refined and published. ${ }^{16,25}$ Since then, most surgeons have ceased performing these operations for small pineal cysts in the absence of hydrocephalus. ${ }^{3}$

\section{Natural History of CSP Cysts}

The natural history of CSP cysts is unknown, and our small series gives only a glimpse at this rare entity. Due to the retrospective nature of this series, we could not elaborate on the denominator, or on other nonoperated similar cases.

We speculate that the 2 cases in which the cyst size decreased could represent a spontaneous rupture of the cysts to the lateral or third ventricles. A similar mechanism has been suggested for spontaneous regression of other arachnoid cysts, either by secondary rupture following a traumatic tear, or a rupture following cyst enlargement (secondary to osmotic changes). ${ }^{10,20}$

\section{Treatment of CSP Cysts}

The main purpose of treatment is to relieve the pressure 
effect of the cyst. This can be achieved through the following surgical techniques: 1) craniotomy and open fenestration of cyst, 2) placement of a ventriculoperitoneal or cystoperitoneal shunt, 3) stereotactic fenestration, and 4) neuroendoscopic cystoventriculostomy.

Prior to the 1990s the main technique used was craniotomy and fenestration of cyst. Subsequently, stereotactic fenestration was used. By the mid-1990s, with the introduction of neuroendoscopy, endoscopic cystoventriculostomy became the surgery of choice. , $12,17,24^{2}$

However, approaching the cavum endoscopically through small frontal horns may be dangerous! The endoscope entry can cause tissue damage to surrounding parenchyma and bleeding, all within a limited and sometimes distorted cavity. We advocate that if endoscopic cystoventriculostomy is indicated, the endoscope should be calibrated as a navigation tool-to assist anatomical orientation and precision.

Our current treatment paradigm for CSP cysts includes a baseline neurological and ophthalmological evaluation. Children who are neurologically intact and have no associated hydrocephalus are re-examined every few weeks or months, according to their clinical condition. A follow-up MRI is recommended in any case of clinical deterioration, or about 6-12 months after the initial evaluation. We have not performed ICP monitoring in our patients with CSP cysts. However, in selected patients with headaches who do not present with hydrocephalus, ICP measurement may have a role in trying to correlate the complaint and the cyst. Surgery is recommended for symptomatic patients who harbor CSP cysts associated with hydrocephalus.

\section{Conclusions}

Spontaneous resolution of CSP cysts may be under-reported. When patients present with no hydrocephalus, we recommend conservative management with clinical and radiological follow-up. In patients with secondary hydrocephalus, endoscopic cystoventriculostomy is an option.

\section{References}

1. Aboulker J, Pradat P, Metzger J, Harispe L, Dodan N, Bringer B: [Intracranial hypertension due to septal cyst blocking Monro's foramen.] Neurochirurgie 14:901-907, 1968 (Fr)

2. Abu-Arafeh I, Razak S, Sivaraman B, Graham C: Prevalence of headache and migraine in children and adolescents: a systematic review of population-based studies. Dev Med Child Neurol 52:1088-1097, 2010

3. Al-Holou WN, Terman SW, Kilburg C, Garton HJ, Muraszko KM, Chandler WF, et al: Prevalence and natural history of pineal cysts in adults. J Neurosurg 115:1106-1114, 2011

4. Amin BH: Symptomatic cyst of the septum pellucidum. Childs Nerv Syst 2:320-322, 1986

5. Aoki N: Cyst of the septum pellucidum presenting as hemiparesis. Childs Nerv Syst 2:326-328, 1986

6. Autret A, Valade D, Debiais S: Placebo and other psychological interactions in headache treatment. J Headache Pain 13:191-198, 2012

7. Borha A, Ponte KF, Emery E: Cavum septum pellucidum cyst in children: a case-based update. Childs Nerv Syst 28:813-819, 2012

8. Chiu CD, Huang WC, Huang MC, Wang SJ, Shih YH, Lee LS: Navigator system-assisted endoscopic fenestration of a symptomatic cyst in the septum pellucidum - technique and cases report. Clin Neurol Neurosurg 107:337-341, 2005

9. Dandy WE: Congenital cerebral cyst of the cavum septi pellucidi (fifth ventricle) and cavum vergae (sixth ventricle). Arch Neurol Psychiatry 25:44-66, 1931

10. Dodd RL, Barnes PD, Huhn SL: Spontaneous resolution of a prepontine arachnoid cyst. Case report and review of the literature. Pediatr Neurosurg 37:152-157, 2002

11. Hong Y, Chen S, Guo SX, Zhang JM: Spontaneous resolution of a cyst of the septum pellucidum. Am J Med Sci 342:333335,2011

12. Jackowski A, Kulshresta M, Sgouros S: Laser-assisted flexible endoscopic fenestration of giant cyst of the septum pellucidum. Br J Neurosurg 9:527-531, 1995

13. Kansu T, Bertan V: Fifth ventricle with bitemporal hemianopsia. Case report. J Neurosurg 52:276-278, 1980

14. Koçer N, Kantarci F, Mihmalli I, Işlak C, Cokyüksel O: Spontaneous regression of a cyst of the cavum septi pellucidi. Neuroradiology 42:360-362, 2000

15. Lancon JA, Haines DE, Raila FA, Parent AD, Vedanarayanan VV: Expanding cyst of the septum pellucidum. Case report. J Neurosurg 85:1127-1134, 1996

16. Lapras C, Patet JD, Mottolese C, Lapras C Jr: Direct surgery for pineal tumors: occipital-transtentorial approach. Prog Exp Tumor Res 30:268-280, 1987

17. Meng H, Feng H, Le F, Lu JY: Neuroendoscopic management of symptomatic septum pellucidum cysts. Neurosurgery 59:278-283, 2006

18. Oteruelo FT: On the cavum septi pellucidi and the cavum Vergae. Anat Anz 162:271-278, 1986

19. Sayama CM, Harnsberger HR, Couldwell WT: Spontaneous regression of a cystic cavum septum pellucidum. Acta Neurochir (Wien) 148:1209-1211, 2006

20. Seizeur R, Forlodou P, Coustans M, Dam-Hieu P: Spontaneous resolution of arachnoid cysts: review and features of an unusual case. Acta Neurochir (Wien) 149:75-78, 2007

21. Stovner Lj, Hagen K, Jensen R, Katsarava Z, Lipton R, Scher A, et al: The global burden of headache: a documentation of headache prevalence and disability worldwide. Cephalalgia 27:193-210, 2007

22. Tamburrini G, D’Angelo L, Paternoster G, Massimi L, Caldarelli M, Di Rocco C: Endoscopic management of intra and paraventricular CSF cysts. Childs Nerv Syst 23:645651,2007

23. Wang KC, Fuh JL, Lirng JF, Huang WC, Wang SJ: Headache profiles in patients with a dilatated cyst of the cavum septi pellucidi. Cephalalgia 24:867-874, 2004

24. Weyerbrock A, Mainprize T, Rutka JT: Endoscopic fenestration of a symptomatic cavum septum pellucidum: technical case report. Neurosurgery 59:ONSE491, 2006

25. Wisoff JH, Epstein F: Surgical management of symptomatic pineal cysts. J Neurosurg 77:896-900, 1992

26. Wong ST, Moes G, Ernest K, Zovickian J, Kim JY, Pang D: Innervation of the brain, intracerebral Schwann cells and intracerebral and intraventricular schwannomas. Childs Nerv Syst 30:815-824, 2014

\section{Author Contributions}

Conception and design: Roth, Constantini. Acquisition of data: Bot. Analysis and interpretation of data: all authors. Drafting the article: Roth, Bot. Critically revising the article: all authors. Reviewed submitted version of manuscript: all authors. Study supervision: Roth, Constantini.

\section{Correspondence}

Jonathan Roth, Department of Pediatric Neurosurgery, Dana Children's Hospital, Tel-Aviv Medical Center, 6 Weizman St., Tel-Aviv 64239, Israel. email: jonaroth@gmail.com. 